\title{
Assessment of Anxiety at Three Different Point of Adult Elective Surgical Patient
}

\author{
Dr. AKM Faizul Hoque ${ }^{1 *}$, Dr. Jeevan Pacchad ${ }^{2}$, Dr. Ashfaqul Islam ${ }^{3}$, Dr. Farida Khan ${ }^{4}$, Dr. Moinuddin ${ }^{5}$, Dr. Ranjan
} Kumar Nath ${ }^{6}$

\author{
${ }^{1}$ Associate Professor, Anaesthesia Analgesia and ICU, BSMMU, Shahbag, Dhaka, Bangladesh \\ ${ }^{2}$ Consultant Anaesthesia, Anaesthesia and Pain, Lifeline Medical Institute of Science and Research, Dhaka, Bangladesh \\ ${ }^{3}$ Medical Officer, Anaesthesia Analgesia and ICU, BSMMU, Shahbag, Dhaka, Bangladesh \\ ${ }^{4}$ Consultant, Gyne and obstetrics, Central Police Hospital, Dhaka, Bangladesh \\ ${ }^{5}$ Medical Officer, OSD, DGHS, Mohakhali, Dhaka, Bangladesh \\ ${ }^{6}$ Professor, Dept. of Anaesthesia, Chattogram Medical College, Chattogram, Bangladesh
}

*Corresponding author: Dr. AKM Faizul Hoque

\section{Abstract}

Background: Anxiety is a common experience it occurs adult patients undergoing elective surgery. It may alter autonomic and neuroendocrine function leading to increased anaesthetic consumption, delayed recovery, postoperative pain, prolonged hospital staying. Preoperative anxiety level and responsible factors should be measured. Objective: To evaluates the anxiety level at different time points during preoperative period in adults undergoing elective surgery. Methodology: This observational study was conducted on 117 patients of 18 -65 years and ASA I \& II who were presented for surgery at Bangabandhu Sheikh Mujib Medical University from Jan-Dec2018. Consecutive sampling data were collected using sociodemographic and APAIS questionnaire. All data are collected analyses by using SPSS version 20 software. A p-value $\leq 0.05$ was considered as statistically significant. Results: Adult patients undergoing elective surgery had significant anxiety at PACU $67.5 \%$ followed by holding area $66.5 \%$ and before induction $24 \%$. Female sex, younger age, previous surgery had higher anxiety. Conclusion: High prevalence of preoperative anxiety in adult surgical patients in the preanesthetic checkup unit, holding area and before induction of anesthesia but more anxious about anesthesia than surgery at holding area. Anxiolytics significantly reduce pulse, blood pressure and anxiety. Patient with intermediate and major type of surgery and younger age, low educational level and women had higher anxiety.

Keywords: Anxiety, Adult Elective Surgical Patient.

Copyright $($ C) 2021 The Author(s): This is an open-access article distributed under the terms of the Creative Commons Attribution 4.0 International License (CC BY-NC 4.0) which permits unrestricted use, distribution, and reproduction in any medium for non-commercial use provided the original author and source are credited.

\section{INTRODUCTION}

Anxiety is an emotional state of fear, nervousness and worry about threatening events associated with the physiological alertness [1]. Anxiety may define as an emotional state manifests as an unease, worry and nervousness associated with physical changes [2]. It is a response to external or internal stimuli that can have behavioral, emotional, cognitive and physical symptoms [3]. Patient with higher level of anxiety needs more anaesthetic, more postoperative analgesics and prolonged hospital staying [4].

Perioperative period is one of the worrying events for most surgical patients. It often triggers emotional, cognitive and physiological responses. The source of anxiety is often nonspecific and unknown to individual [5] but known to cause abnormal hemodynamics as a consequence of autonomic and endocrine stimulation [6]. The elevated levels of preoperative anxiety alter anaesthetic and analgesics consumptions [7] that increase the risk of postoperative complications such as pain, prolonged recovery, longer hospitalization, and death [8]. Although surgical techniques have been improving and becoming much safer, studies reported $60-80 \%$ of surgical patients [9] experience considerable preoperative anxiety.

The degree to which each patient manifests anxiety depends on many factors such as the patient's susceptibility to preoperative anxiety, age, gender, past experiences and type and extent of the proposed surgery, current health and socioeconomic status reported to be associated with preoperative anxiety [10]. 
The elevated levels of preoperative anxiety have serious outcomes and can increase the risk of postoperative complications such as pain, prolonged recovery, longer hospitalization, and death [11]. The response to anesthesia and analgesia in anxious patients is different when compared with non-anxious patients. anxiety may also increase the requirement of anesthesia and risk of awareness during surgery [12]. The common causes of preoperative anxiety include fear for loss of physical capacity and worry about family members and children [13]. Physical injury, complications and death.

The level of preoperative anxiety can be reduced by pharmacological therapy [14] as well as non-pharmacological methods such as spiritual practices, music, provision of information and social support [15]. Assessment and provision for psychological and pharmacological support is required to allay preoperative anxiety [16].

There are several modalities currently available to assess preoperative anxiety including StateTrait Anxiety Inventory, STAI [17]; Amsterdam Preoperative Anxiety and Information Scale (APAIS), [18]; Goldberg Anxiety Scale, GADS [19]; Visual Analogue Scale for Anxiety, VAS-A [20]) Depression, Anxiety and Stress Test, DASS [21]; Hospital Anxiety and Depression, HADS [22].

State-Trait Anxiety Inventory (STAI), is popular to measure preoperative anxiety. The STAI has two questionnaires; each consists of 20 items to assess 'trait' anxiety and 'state' anxiety. The STAI is time consuming and does not provide any information to the patient.

The Amsterdam Preoperative Anxiety and Information Scale (APAIS) were developed by Moermann et al. in 1996. A subjective method developed particularly for the preoperative patient, which measures anxiety level and need for information about surgery and anesthesia.

It is a self-reported questionnaire of six items of three components divided into two sections anxiety and need for information. Anxiety related to anaesthesia and surgery assessed separately and their summation represents anxiety. The measure of agreement in the APAIS scalerated on a five-point Likert scale from "not at all" 1 to "extremely" 5 [24].

Preoperative anxiety level was assessed in 117 normotensive patients at three different time points (preanesthetic checkup clinic, holding area and 30 minutes after administration of an anxiolytic just before induction of anesthesia) were evaluated.

\section{Materials And Methods}

This Observational study was undertaken after receiving ethical clearance at the Department of Anesthesia, Analgesia and Intensive Care Medicine of Bangabandhu Sheikh Mujib Medical University (BSMMU), from January 2018 to March 2019

All patients of ASA grade I \& II of $18-65$ years old, arrived at the preanesthetic check-up clinic for next day surgery were enrolled and consecutive sampling of 117 subject had taken. Hypertension, ischemic heart disease, anxiety related disorders or any anti-anxiety or anti-depressant medications were excluded. Data was processed and analyzed using computer-based software, Statistical package for Social Science (SPSS) version 23 software and application of standard statistical tools.

\section{Outcome variables}

$\begin{array}{ll}\text { a. } & \text { Anxiety level }(25) \\ & \text { High }>10 \\ \text { b. } & \text { Low } \leq 10 \\ \text { c. }(18-33,34-49,50-65 \text { years }) \\ \text { d. } & \text { Type of surgery (minor, intermediate, major) } \\ \text { e. } & \text { Type of anesthesia (general, regional, combined) } \\ \text { f. } & \text { Education level (SSC and above, below SSC) }\end{array}$

The APAIS has 6 items comprised of two primary factors, anxiety and need for information divide into three parts; anesthesia related anxiety (items $1+2$ ), surgery related anxiety $4+5$ and need for information item 3+6. Anaesthesia and surgery related anxiety assesses separately and their summation represents anxiety scale. The need for information assessed by item $3+5$ that score ranges from 2 to 10 .

The measure of agreement graded on a 5-point Likert scale, from $1=$ not at all, to $5=$ extremely. The anxiety scale ranging from 4 to 20 . The result interpreted as minimal or no anxiety when score $\leq 10$ and high anxiety if $>10$ ). The need for information score ranges from 2 to 10 ; minimal or no information 2$5, \geq 5$ more information requirement.

Preoperative anxiety level was assessed in 117 normotensive patients undergoing surgical care at three different time points (preanesthetic checkup clinic, holding area and 30 minutes after administration of an anxiolytic at holding area and another set of data taken just before induction of anesthesia) were evaluated.

\section{Results \& OBSERVATIONS}

Total 117 normotensive patient undergoing elective surgery were assessed for anxiety and need for information at three different time points i.e. preanesthetic checkup clinic(T1), holding area(T2) and just before induction of anesthesia(T3). 
Table-I: Demographic presentation $(\mathrm{N}=117)$

\begin{tabular}{|l|l|l|}
\hline Demographic presentation $(\mathbf{N}=117)$ \\
\hline \multirow{4}{*}{ Gender } & Male & $59(50.4)$ \\
\cline { 2 - 3 } & Female & $49(49.6)$ \\
\hline \multirow{4}{*}{ Education } & $18-33$ years & $47(40.2)$ \\
\cline { 2 - 3 } & $34-49$ years & $40(34.2)$ \\
\cline { 2 - 3 } & $50-71$ years & $30(25.6)$ \\
\hline Anaesthesia type & Below SSC & $67(57.3)$ \\
\cline { 2 - 3 } & Above HSC & $50(42.7)$ \\
\cline { 2 - 3 } & GA & $82(70.1)$ \\
\hline \multirow{4}{*}{$\begin{array}{l}\text { Surgery } \\
\text { Type }\end{array}$} & Regional & $26(22.2)$ \\
\cline { 2 - 3 } & Combined & $9(7.7)$ \\
\cline { 2 - 3 } & Minor & $14(12.0)$ \\
\cline { 2 - 3 } & Intermediate & $55(47.0)$ \\
\hline
\end{tabular}

Anxiety level was also researched according to the demographic variables (age, gender, education level, type of anesthesia and surgery) and APAIS variables.and the effect of anxiolytic on high anxiety at holding area.

Table-II : Age and Anxiety level at different time before surgery $(n=117)$

\begin{tabular}{|l|l|l|l|l|l|l|}
\hline $\begin{array}{l}\text { Age (years) } \\
\mathbf{n = 1 1 7 ,} \%\end{array}$ & At PACU & \multicolumn{2}{l|}{ At holding area } & \multicolumn{2}{l|}{ Before induction anesthesia } \\
\cline { 2 - 7 } & High anxiety & Low anxiety & High anxiety & Low anxiety & High anxiety & Low anxiety \\
\hline $\begin{array}{l}18-33 \\
47,(40.2)\end{array}$ & $36(30.8)$ & $\begin{array}{l}11 \\
(9.4)\end{array}$ & $\begin{array}{l}34 \\
(29.05)\end{array}$ & $13(10.8)$ & $\begin{array}{l}10 \\
(8.5)\end{array}$ & $37(31.6)$ \\
\hline $\begin{array}{l}34-49 \\
40,(34.2)\end{array}$ & $29(24.8)$ & $\begin{array}{l}11 \\
(9.4)\end{array}$ & $30(25.6)$ & $\begin{array}{l}10 \\
(8.5)\end{array}$ & $\begin{array}{l}14 \\
(11.9)\end{array}$ & $26(22.2)$ \\
\hline $\begin{array}{l}50-65 \\
30,(25.6)\end{array}$ & $\begin{array}{l}14 \\
(11.9)\end{array}$ & $16(13.7)$ & $14(11.9)$ & $16(13.7)$ & $8(6.9)$ & $22(18.9)$ \\
\hline p-value & 0.017 & & 0.026 & 0.002 & \\
\hline
\end{tabular}

Chi-square test was done to measure the level of significance. Values are expressed significant if $\mathrm{p}<0.05$. All participants at different time points i.e. at preanesthetic checkup clinic, holding area had statistically significant anxiety. ( $\mathrm{p}$ value were 0.017 , 0.026 respectively lower than $\mathrm{p}<0.05$. Anxiolytic significantly reduced anxiety in all ages before induction of anesthesia where $(32,27.35 \% ; 85 \mathrm{n}$ $72.64 \%, \mathrm{p}=0.002)$.

Anxiety level and gender: Women had high anxiety in PACU (36.7\%), holding area (39.3\%) and before induction of anesthesia $(11.9 \%)$ to male but statistically significant only in the holding area ( $\mathrm{p}$ value $=0.004)$.

Table-III: Gender and Anxiety level at different time before surgery $(n=117)$

\begin{tabular}{|l|l|l|l|l|l|l|}
\hline \multirow{2}{*}{$\begin{array}{l}\text { Type of anesthesia } \\
\text { N=117 }\end{array}$} & \multicolumn{2}{|l|}{ At PACU } & \multicolumn{2}{l|}{ At holding area } & \multicolumn{2}{l|}{ Before anesthesia } \\
\cline { 2 - 7 } & High anxiety & Low anxiety & High anxiety & Low anxiety & High anxiety & Low anxiety \\
\hline GA 82 (70.1) & $57(48.6)$ & $25(21.6)$ & $59(50.4)$ & $23(19.6)$ & $16(13.7)$ & $66(56.4)$ \\
\hline Regional 26 (22.2) & $17(14.4)$ & $9(7.7)$ & $13(11.1)$ & $13(11.1)$ & $6(5.1)$ & $20(17.2)$ \\
\hline Combined 9 (7.7) & $5(4.3)$ & $4(3.4)$ & $6(5.1)$ & $3(2.7)$ & $2(1.7)$ & $7(5.9)$ \\
\hline p-value & 0.674 & 0.118 & & 0.918 & \\
\hline
\end{tabular}

Chi-square test was done to measure the level of significance. Values are expressed significant if $\mathrm{p}<0.05$.

Table-IV: Type of anesthesia and Anxiety level at different time before surgery (n=117)

\begin{tabular}{|l|l|l|l|l|l|l|}
\hline \multirow{2}{*}{$\begin{array}{l}\text { Gender } \\
\mathbf{n}=117\end{array}$} & \multicolumn{2}{|l|}{ At PACU } & \multicolumn{2}{l|}{ At holding area } & \multicolumn{2}{l|}{$\begin{array}{l}\text { Before induction of } \\
\text { anesthesia }\end{array}$} \\
\cline { 2 - 7 } & $\begin{array}{l}\text { High } \\
\text { anxiety }\end{array}$ & $\begin{array}{l}\text { Low } \\
\text { anxiety }\end{array}$ & $\begin{array}{l}\text { High } \\
\text { anxiety }\end{array}$ & $\begin{array}{l}\text { Low } \\
\text { anxiety } \\
\text { anxiety }\end{array}$ & $\begin{array}{l}\text { Low } \\
\text { anxiety }\end{array}$ \\
\hline $\begin{array}{l}\text { Male } \\
59(50.4)\end{array}$ & $36(30.8)$ & $23(19.7)$ & $32(27.3)$ & $27(23.1)$ & $10(8.6)$ & $49(41.9)$ \\
\hline Female 58 (49.6) & $43(36.7)$ & $15(12.8)$ & $46(39.3)$ & $12(10.3)$ & $14(11.9)$ & $44(37.6)$ \\
\hline p-value & 0.130 & \multicolumn{3}{|l|}{0.004} & 0.336 & \\
\hline
\end{tabular}

Chi-square test was done to measure the level of significance. Values are expressed significant if $\mathrm{p}<0.05$. 
AKM Faizul Hoque et al; Sch J App Med Sci, Mar, 2021; 9(3): 487-492

Table IV shows majority participants had high anxiety at PACU $(79,67.52 \%)$ and at holding area $(66.66 \%)$ and low $(93, .52 \%)$ after anxiolytic before induction of anaethesia which were statistically insignificant.

Table-V: Anxiety score between anesthesia and surgery at different time before surgery

\begin{tabular}{|l|l|l|l|}
\hline \multirow{2}{*}{} & \multicolumn{2}{|l|}{ Anxiety score } & \multirow{2}{*}{ p-value } \\
\cline { 2 - 4 } & $\begin{array}{l}\text { Anesthesia } \\
(\text { Mean } \pm \text { SD)(N=117) }\end{array}$ & $\begin{array}{l}\text { Surgery } \\
(\text { Mean } \pm \text { SD)(N=117) }\end{array}$ & \\
\hline At PACU & $6.01 \pm 1.91$ & $6.02 \pm 1.69$ & 0.961 \\
\hline At Holding area & $6.21 \pm 1.87$ & $5.91 \pm 1.60$ & 0.002 \\
\hline Before induction of anaesthesia & $4.83 \pm 1.50$ & $4.86 \pm 1.36$ & 0.750 \\
\hline
\end{tabular}

Table-VI: Overall anxiety level at different time points before surgery

\begin{tabular}{|l|l|l|}
\hline Anxiety level & High anxiety & Low anxiety \\
\hline At PACU $(\mathrm{n}=117)$ & $79(67.5)$ & $38(32.5)$ \\
\hline At holding area $(\mathrm{n}=117)$ & $78(66.7)$ & $39(33.3)$ \\
\hline Before induction of Anesthesia $(\mathrm{n}=117)$ & $24(20.5)$ & $93(79.5)$ \\
\hline P value & The $\mathrm{p}$-value is $<0.00001$. The result is significant at $\mathrm{p}<.05$. \\
\hline
\end{tabular}

Values are expressed as mean \pm SD: analysis was done by paired t-test. Values were expressed as significant if $\mathrm{p}<0.05$.

Only at holding area (T2) mean values for anxiety score between anesthesia and surgery are found statistically significant $(\mathrm{p}=0.002)$ but other two time point PACU and before induction of anesthesia were statistically insignificant $(\mathrm{p}=0.961, \mathrm{p}=0.750)$ respectively.

Table VI shows 79 subjects $(67.5 \%)$ had high anxiety level at PACU, 78 subjects $(66.7 \%)$ had high anxiety level at holding area and 93 subjects (79.5\%) had low anxiety level before the induction of anesthesia which were

General distribution curve of preoperative anxiety score in three different time points, revealed that anxiety score 11-15 was the highest in number of patients in both PACU and holding area and highest number of patients scored 6-10 after anxiolytic before induction of anesthesia preoperatively.

\section{DiscusSiON}

Anxiety is a common problem in the preoperative settings ranging from 20 to $80 \%$ and remain mostly overlooked. Improvement of anaesthesia care surgical technique didn't help patient to reduce anxiety. APAIS scale was used to evaluate anxiety and considered high if score is $>10$ and low $\leq 10$.

Most of the studied populations of different age group had suffered high anxiety at different time point of care at PACU $(67.5 \%)$ and holding area $(66.7 \%)$ and anxiolytic in the holding area reduce anxiety in $79.5 \%$ before anesthesia. Literature review showed that anxiety increased steadily from the night before surgery, when transferred from ward to the holding area and become peaked sharply prior to anesthetics [25-27].
This study showed that younger adult were the most vulnerable (18-33 years, $40.2 \%)$ to anxiety in PACU and holding area compared to other age groups (34 - 49, 34.2\%), (50-65, 25.6\%) however, all ages responded to anxiolytics. Though older people suffer state anxiety but doesn't affects the feeling of stress and correlation between anxiety and age [28, 29].

Anxiety affected both sexes at different time point of surgical care however, but women had more anxiety at the holding area $66.66 \%$ where $\mathrm{P}=0.004$, well below $\mathrm{p}<0.05$. Another study supports this result [25]. Altered levels of estrogen and progesterone (30) due to stress and easier expression of anxiety by the female may play important role [31]. Actually gender alone had no relation with preoperative anxiety levels (32) Anxiety is common for different type of anesthesia and surgery at different time point though majority patient with proposed type of surgery and anesthesia had no significant anxiety.

Low educational background associated with more anxiety $73.4 \%$, and $59.0 \%$ at PACU and holding which were statically insignificant. Educational level of the had no influence on the feeling of stress and thus anxiety [31].

Anxiolytic at the holding area significantly reduced $(\mathrm{P}<0.001)$ high anxiety before induction of anesthesia in all age sex educational irrespective of anesthesia.

Study suggested night before and following morning on the day of surgery anxiolytic premedication effectively reduced anxiety [14].

The mean anxiety scores between anesthesia and surgery only significant in the holding area $(6.21 \pm$ $1.87,5.91 \pm 1.60 ; \mathrm{p}=0.002)$ which were relevant to the studies [20, 27, 29, 30]. 


\section{CONCLUSION}

From this observational study, it is concluded that over all anxiety exists throughout the preoperative period and more intense at the holding area at morning on the day of planned anesthesia and surgery. However, young adult, female, low educational level and who were underwent general anesthesia and /or intermediate and major type of surgery had high anxiety in the preanesthetic checkup clinic and in the holding area and but more anxious related to anesthesia in the holding area. However, anxiolytic in the holding area reduced anxiety before induction of anesthesia. So, preoperative anxiety evaluation and premedication especially at the holding area for all elective anaesthesia and surgery in adult should routinely be available.

\section{REFERENCES}

1. Julian LJ. Measures of anxiety: State-Trait Anxiety Inventory (STAI). Beck Anxiety Inventory (BAI), and. 2011.

2. Mulugeta H, Ayana M, Sintayehu M, Dessie G, Zewdu T. Preoperative anxiety and associated factors among adult surgical patients in Debre Markos and Felege Hiwot referral hospitals, Northwest Ethiopia. BMC anesthesiology. 2018 Dec;18(1):1-9.

3. Robleda G, Sillero-Sillero A, Puig T, Gich I, Baños JE. Influence of preoperative emotional state on postoperative pain following orthopedic and trauma surgery. Revista latino-americana de enfermagem. 2014 Oct;22(5):785-91.

4. Vargas TV, Maia EM, Dantas RA. Patient feelings during the preoperative period for cardiac surgery. Revista latino-americana de enfermagem. 2006 Jun;14(3):383-8.

5. Ryamukuru D. Assessment of preoperative anxiety for patients awaiting surgery at UTHK (Doctoral dissertation, University of Rwanda).

6. Kil HK, Kim WO, Chung WY, Kim GH, Seo H, Hong JY. Preoperative anxiety and pain sensitivity are independent predictors of propofol and sevoflurane requirements in general anaesthesia. British journal of anaesthesia. 2012 Jan 1;108(1):119-25.

7. Kain ZN, Mayes LC, Caldwell-Andrews AA, Karas DE, McClain BC. Preoperative anxiety, postoperative pain, and behavioral recovery in young children undergoing surgery. Pediatrics. 2006 Aug 1;118(2):651-8.

8. Bailey, L. (2010). Strategies for decreasing patient anxiety in the perioperative setting. AORN journal, 92(4), 445-460.

9. Nigussie S, Belachew T, Wolancho W. Predictors of preoperative anxiety among surgical patients in Jimma University specialized teaching hospital, South Western Ethiopia. BMC surgery. 2014 Dec;14(1):1-0.

10. Kain ZN, Mayes LC, Caldwell-Andrews AA, Karas DE, McClain BC. Preoperative anxiety, postoperative pain, and behavioral recovery in young children undergoing surgery. Pediatrics. 2006 Aug 1;118(2):651-8.

11. Jlala HA, French JL, Foxall GL, Hardman JG, Bedforth NM. Effect of preoperative multimedia information on perioperative anxiety in patients undergoing procedures under regional anaesthesia. British journal of anaesthesia. 2010 Mar 1;104(3):369-74.

12. Caumo W, Schmidt AP, Schneider CN, Bergmann J, Iwamoto CW, Bandeira D, Ferreira MB. Risk factors for preoperative anxiety in adults. Acta Anaesthesiologica $\quad$ Scandinavica. 2001 Mar;45(3):298-307.

13. Islam MS, Banik D, Akhtaruzzaman AK, Sarker PC, Igbal KM. Use of Oral Bromazepam as Premedicant and it $\mathrm{s}$ Effects in Peri-operative Period-A Comparative Study with Oral Diazepam. Journal of the Bangladesh Society of Anaesthesiologists. 2005:22-30.

14. Kalkhoran MA, Karimollahi M. Religiousness and preoperative anxiety: a correlational study. Annals of general psychiatry. 2007 Dec;6(1):1-5.

15. Walker JA. Emotional and psychological preoperative preparation in adults. British journal of nursing. 2002 Apr 25;11(8):567-75.

16. Grös DF, Antony MM, Simms LJ, McCabe RE. Psychometric properties of the state-trait inventory for cognitive and somatic anxiety (STICSA): comparison to the state-trait anxiety inventory (STAI). Psychological assessment. 2007 Dec;19(4):369.

17. Moerman N, van Dam FS, Muller MJ, Oosting H. The Amsterdam preoperative anxiety and information scale (APAIS). Anesthesia \& Analgesia. 1996 Mar 1;82(3):445-51.

18. Montón C, MJ PE, Campos R, Lobo A. Anxiety scales and Goldberg's depression: an efficient interview guide for the detection of psychologic distress. Atencion primaria. 1993 Oct 1;12(6):3459.

19. Kindler CH, Harms C, Amsler F, Ihde-Scholl T, Scheidegger D. The visual analog scale allows effective measurement of preoperative anxiety and detection of patients' anesthetic concerns. Anesthesia \& Analgesia. 2000 Mar 1;90(3):706-12.

20. Crawford JR, Henry JD. The Depression Anxiety Stress Scales (DASS): Normative data and latent structure in a large non- clinical sample. British journal of clinical psychology. 2003 Jun;42(2):11131.

21. Zigmond AS, Snaith RP. The hospital anxiety and depression scale. Acta Psychiatr Scand. 1983;67:361-70

22. Spielberger CD, Sydeman SJ. State Trait Anxiety Inventory and State-Trait Anger Expression Inventory, The Use of Psychological Tests for Treatment Planning and Outcome Assessment. Edited by: Maruish ME. Hillsdale, LEA. 1994:292-321 
AKM Faizul Hoque et al; Sch J App Med Sci, Mar, 2021; 9(3): 487-492

23. Boker A, Brownell L, Donen N. The Amsterdam preoperative anxiety and information scale provides a simple and reliable measure of preoperative anxiety. Can J Anaesth. 2002, 49: 792-798. 10.1007/BF03017410

24. Badner NH, Nielson WR, Munk S, Kwiatkowska C, Gelb AW. Preoperative anxiety: detection and contributing factors. Canadian Journal of Anaesthesia. 1990 May 1;37(4):444.

25. Carr E, Brockbank K, Allen S, Strike P. Patterns and frequency of anxiety in women undergoing gynaecological surgery. Journal of clinical nursing. 2006 Mar;15(3):341-52.

26. Pokharel K, Bhattarai B, Tripathi M, Khatiwada S, Subedi A. Nepalese patients' anxiety and concerns before surgery. Journal of clinical anesthesia. 2011 Aug 1;23(5):372-8.
27. Moerman N, van Dam FS, Muller MJ, Oosting H. The Amsterdam preoperative anxiety and information scale (APAIS). Anesthesia \& Analgesia. 1996 Mar 1;82(3):445-51.

28. Jafar MF, Khan FA. Frequency of preoperative anxiety in Pakistani surgical patients. Journal of the Pakistan Medical Association. 2009; 59(6):359.

29. Cevik B. The evaluation of anxiety levels and determinant factors in preoperative patients. International Journal of Medical Research \& Health Sciences. 2018;7(1):135-43.

30. Rosiek A, Kornatowski T, Rosiek-Kryszewska A, Leksowski Ł, Leksowski K. Evaluation of stress intensity and anxiety level in preoperative period of cardiac patients. BioMed research international. 2016 Mar 2; 2016. 